\title{
Creutzfeldt-Jakob disease in England and Wales, 1980-1984: a case-control study of potential risk
} factors

\author{
R HARRIES-JONES, ${ }^{*}$ R KNIGHT, ${ }^{*}$ R G WILL, ${ }^{*}$ S COUSENS, $\dagger$ P G SMITH, $\dagger$ \\ W B MATTHEWS* \\ From the University Department of Clinical Neurology, ${ }^{*}$ the Radcliffe Infirmary, Oxford and the London School \\ of Hygiene and Tropical Medicine, $\dagger U K$
}

SUMMARY An attempt was made to ascertain all cases of Creutzfeldt-Jakob disease occurring in England and Wales during the 5 year period 1980-1984. The mean annual mortality rate was $0.49 /$ million; women were more frequently affected than men. The age-specific mortality rate reached a peak in the seventh decade. A case-control study involving 92 of the 122 definite and probable cases ascertained failed to confirm the reality of previously suspected aetiological agents in the environment. Although there was no confirmed instance of familial Creutzfeldt-Jakob disease in the case-control study, dementia in close relatives was significantly more common than in controls.

Since Creutzfeldt-Jakob disease was first shown to be transmissible to laboratory animals ${ }^{1}$ there has been continued speculation on the possibility of natural transmission of the disease. Probable iatrogenic transmission has been reported on a number of occasions ${ }^{2-7}$ but no natural route of transmission has been conclusively demonstrated. Potential risk factors have been examined in a number of necessarily small case-control studies, but with conflicting results. ${ }^{8-13}$

We here report epidemiological data from a national 5 year survey of Creutzfeldt-Jakob disease in England and Wales.

\section{Methods and study population}

Neurological centres in England and Wales were already aware of our interest in Creutzfeldt-Jakob disease and were repeatedly circulated with requests to notify us of all known or suspected cases of the disease. Copies of all death certificates on which Creutzfeldt-Jakob disease or spongiform encephalopathy was mentioned were obtained from the Office of Population, Censuses and Surveys (OPCS). Wherever possible. Patients were seen by one of us in life, often repeatedly. When the case was known to us only from death certification, hospital notes were obtained and EEG records were examined. It is unlikely that the pattern of referral

Address for reprint requests: Professor W B Matthews, Sandford House, Sandford on Thames, Oxford, OX4 9YN.

Received 2 February 1988 and in revised form 21 April 1988. Accepted 26 April 1988 introduced bias as cases were ascertained from all Regional neurological centres. The geographical distribution of the cases at the time of onset of the disease and throughout life will be described in a subsequent publication.

Selection of controls. Patients with Creutzfeldt-Jakob disease are invariably demented and information on possible risk factors was obtained through a structured interview with a relative. We attempted to recruit two control patients for each case, matched with the case for age ( \pm 4 years), sex and hospital. One "neurological" control was selected from patients with a neurological disease impossible to mistake for Creutzfeldt-Jakob disease, and a second "medical" control was selected from patients admitted to hospital with a nonneurological condition. Suitable controls were obtained by questioning ward staff and accepting the first proffered matched subject with an appropriate relative willing to take part in an identical interview. In each case-control trio relatives of an identical degree were interviewed whenever possible.

Exclusions. Thirty cases of Creutzfeldt-Jakob disease were excluded from the case-control study for the following reasons: lack of medical cooperation (1), lack of cooperation of relative (3), no informed relative available (12) and inability to find appropriate medical controls in patients admitted to a neurological hospital (3). It was thought undesirable to approach the relatives of 11 patients ascertained from death certificates when there had been prolonged delay in obtaining hospital notes or other confirmation of the diagnosis.

Data collection and analysis. In 80 of the 92 sets of patients 
and controls it was possible to match the degree of relative interviewed, in 62 instances this being the spouse, in 13 offspring and in five a sibling. In the remaining 12 sets exact matching of the degree of relative interviewed was not achieved but in every instance the relationship was close.

In the structured interviews information was particularly sought on factors previously reported to be associated with Creutzfeldt-Jakob disease. These included aspects of diet, particularly consumption of animal products, including brains, medical history, especially surgical procedures, and trauma, contact with animals, occupation and family history of dementia. In control subjects all past medical and surgical events related to the current hospital admission were excluded from consideration. Attention was paid to the interval between past medical events and onset of Creutzfeldt-Jakob disease. In the control subjects "onset" was equated with current hospital admission. A life history of place of residence was also obtained and these data are being analysed for evidence of clustering and will be reported separately.

The statistical analysis of the case-control study was performed using the computer package PECAN retaining the case-control matching. ${ }^{14}$ Significance levels quoted are twosided. The general approach adopted was to compare the cases with each of the control groups separately. If these results were similar an analysis was conducted with the two control groups combined. Otherwise results are given for the two comparisons separately.

Diagnostic criteria. These have been described previously. ${ }^{15}$ Briefly, a history of rapidly advancing dementia, accompanied by varying combinations of the typical signs of Creutzfeldt-Jakob disease (myoclonus, other movement disorders, cortical blindness, cerebellar ataxia, rigidity, akinetic mutism) and histological confirmation of spongiform degeneration were required for "definite" diagnosis. "Probable" cases were patients with similar clinical features, accompanied by an EEG showing generalised $1-2 \mathrm{~Hz}$ triphasic complexes, but with no histology available. "Possible" cases were patients with the same clinical features but for whom no histological confirmation or characteristic EEG was obtained. Patients with more gradual development of dementia, accompanied or followed by evidence of widespread neurogenic atrophy, usually severe, did not satisfy these diagnostic criteria and, despite the occasional finding of spongiform degeneration at necropsy, probably did not have Creutzfeldt-Jakob disease. ${ }^{16}$

\section{Results}

Classification of cases. In the 5 years 1980-1984 249 patients with known or suspected Creutzfeldt-Jakob disease were reported to us or were certified as dying of this disease. Of these 93 ( 39 men and 54 women) were classified as definite Creutzfeldt-Jakob disease. The British patient reported as developing Creutzfeldt-Jakob disease following human growth hormone injections ${ }^{7}$ was not included as the clinical features did not conform to our criteria and the cause of death was not certified as Creutzfeldt-Jakob disease but "viral encephalitis". Twenty nine patients, 13 men
Table 1 Deaths from Creutzfeldt-Jakob disease (definite and probable cases) in England and Wales, 1980-1984. Four cases surviving into 1985 are excluded

\begin{tabular}{lcccccc}
\hline & \multicolumn{2}{l}{ Year of death } & & & & \\
\cline { 2 - 7 } & 1980 & 1981 & 1982 & 1983 & 1984 & Total \\
\hline Male & 8 & 10 & 9 & 9 & 13 & 49 \\
Female & 16 & 13 & 14 & 12 & 14 & 69 \\
Total & 24 & 23 & 23 & 21 & 27 & 118 \\
\hline
\end{tabular}

and 16 women, were diagnosed as probable Creutzfeldt-Jakob disease, one of whom is still alive in a decorticate state after an initial rapid clinical course. ${ }^{1517}$ Twenty two patients classified as possible Creutzfeldt-Jakob disease are not considered further in this report which is confined to the 122 definite and probable cases. One hundred and five suspected cases, including 16 with amyotrophy, were considered not to show the clinical or histological features of Creutzfeldt-Jakob disease or were shown to have some other disease. This does not reflect on the skills of the referring physicians as we had specifically asked to be informed of suspected and early cases.

There was little variation in the annual number of deaths from definite and probable Creutzfeldt-Jakob disease (table 1). Using the 1981 census population of England and Wales of 48.5 million the average annual death rate for Creutzfeldt-Jakob disease was $0 \cdot 49$ /million.

Age at death for the 121 patients who had died by the time of reporting is shown in fig 1 . The mean age was 63.2 years (range 33-82). The mean in men was 62.3 years and in women 63.8 years. Age and sexspecific average annual mortality rates are shown in fig 2 . Mortality rates rose rapidly with age up to about 70 years and then fell markedly. The excess rates in

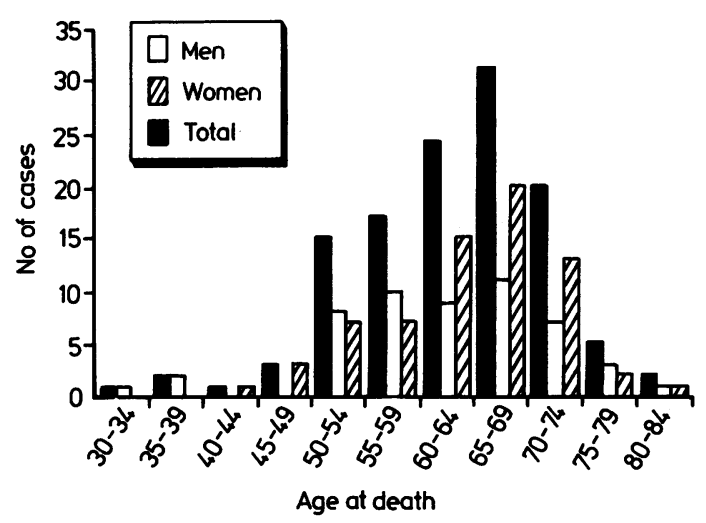

Fig 1 Age at death for 121 definite and probable cases of Creutzfeldt-Jakob disease (includes three cases dying after 1984). 


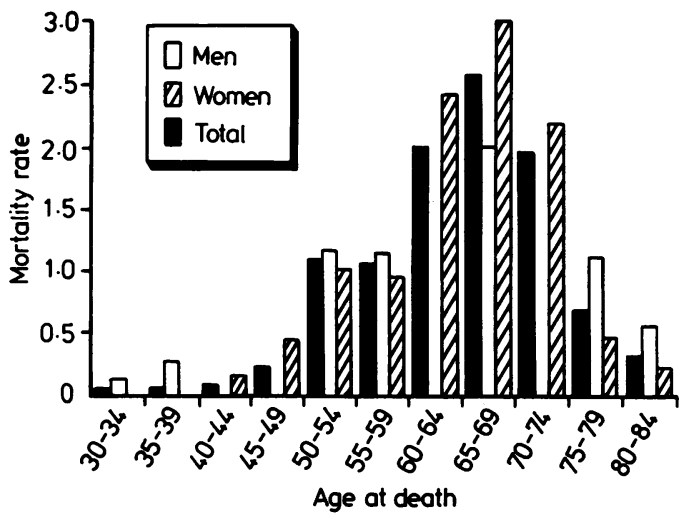

Fig 2 Average annual age and sex-specific mortality rates for definite and probable Creutzfeldt-Jakob disease in England and Wales, 1980-1984.

women were predominantly in the age range $60-74$ years.

In the 111 cases where a detailed family history was obtainable verified Creutzfeldt-Jakob disease in a relative was only present in a single instance. A first degree relative of four other patients died of a subacute dementing disease which might have been Creutzfeldt-Jakob disease.

The age and sex distribution of the 92 patients included in the case-control study is shown in table 2. The mean age of the cases was $63 \cdot 1$ and of the controls $63 \cdot 6$ years.

Socio-economic status. The socio-economic status of each case and control was classified according to the system used by the Registrar General. Status was based, for men and unmarried women, on the most recent occupation, and for married women, on the occupation of their husband. The social class distribution of the cases and the medical controls were not significantly different. The neurological controls, however, tended to be of higher social status $\left(\chi^{2}=\right.$
Table 2 Distribution of 92 cases in case-control study by sex and age.

\begin{tabular}{lllllllllll}
\hline \multicolumn{1}{c}{ Age in years } \\
\cline { 2 - 5 } & $<45$ & $45-49$ & $50-54$ & $55-59$ & $60-64$ & $65-69$ & $70-74$ & $75-79$ & Total \\
\hline Male & 1 & 0 & 7 & 9 & 8 & 10 & 2 & 4 & 41 \\
Female & 0 & 2 & 7 & 3 & 14 & 14 & 9 & 2 & 51 \\
Total & 1 & 2 & 14 & 12 & 22 & 24 & 11 & 6 & 92 \\
\hline
\end{tabular}

4.4, $1 \mathrm{df}$, trend, $\mathrm{p}<0.05$ ). The cases included one doctor, one dentist, three career nurses (one man and two women) and two women with brief nursing experience. Of the control subjects, two women had long service in hospital nursing and two had nursed for 2 and 3 years respectively.

Medical History. No significant differences between cases and controls were found with respect to the following: history of eye operations ( 6 cases; 14 controls), head injury $(17 ; 35)$, jaundice $(8 ; 15)$, receiving blood $(15 ; 37)$, giving blood $(14 ; 20)$, glandular fever $(2 ; 2)$, poliomyelitis $(4 ; 2)$, regular injections (e.g. insulin) $(10 ; 15)$, asthma $(5 ; 11)$, autoimmune disease $(3 ; 9)$ or left-handedness $(12 ; 17)$.

Cases were more likely than controls to have had herpes zoster in adult life (6 cases; 0 controls, $p<$ 0.005). Previous illness requiring psychiatric treatment was significantly more common in cases than in controls $(p<0.05)$, most instances of psychiatric disease being depression or described as "breakdown".

Controls were more likely than cases to have had surgical operations (other than ophthalmic) ( $p<$ $0 \cdot 10$, table 3 ). In particular, 26 cases and 73 controls had undergone organ removal, while 48 cases and 118 controls had undergone operations necessarily involving internal sutures. Seventeen cases and 45 controls had undergone surgery or experienced significant trauma in the 5 years before onset. No case had undergone craniotomy. Subdividing past medical

Table 3 Estimated odds ratios and their 95\% confidence intervals for the most statistically significant associations

\begin{tabular}{|c|c|c|c|c|c|c|}
\hline \multirow[b]{3}{*}{ Risk factor } & \multirow[b]{3}{*}{ Odds ratio } & \multirow{3}{*}{$\begin{array}{l}\text { Approximate } 95 \% \\
\text { confidence limits }\end{array}$} & \multirow[b]{3}{*}{ p value } & \multicolumn{3}{|c|}{ Number of } \\
\hline & & & & \multirow[t]{2}{*}{ Cases } & \multicolumn{2}{|c|}{ Controls } \\
\hline & & & & & Neuro & Medical \\
\hline $\begin{array}{l}\text { Surgery at any time } \\
\text { Zoster in adult life } \\
\text { Current alcohol } \\
\text { Keeping cats } \\
\text { Pets other than cats/dogs } \\
\text { Ferret contact } \\
\text { Mink contact } \\
\text { Dementia in family }\end{array}$ & $\begin{array}{l}0 \cdot 6 \\
2 \cdot 6 \\
0 \cdot 5 \\
2 \cdot 0 \\
4 \cdot 4 \\
2 \cdot 1 \\
8 \cdot 6 \\
3 \cdot 6\end{array}$ & $\begin{array}{l}0.3-1 \cdot 00 \\
2 \cdot 4- \\
0 \cdot 3-0.8 \\
1 \cdot 2-3 \cdot 6 \\
1 \cdot 5-12.7 \\
1 \cdot 0-4 \cdot 2 \\
0.9-77 \cdot 9 \\
1 \cdot 8-7 \cdot 1\end{array}$ & $\begin{array}{l}<0.10 \\
<0.005 \\
<0.005 \\
<0.01 \\
<0.01 \\
=0.05 \\
=0.08 \\
<0.0005\end{array}$ & $\begin{array}{r}57 \\
6 \\
50 \\
34 \\
11 \\
19 \\
4 \\
27\end{array}$ & $\begin{array}{r}68 \\
0 \\
71 \\
15 \\
3 \\
14 \\
1 \\
11\end{array}$ & $\begin{array}{r}68 \\
0 \\
61 \\
27 \\
2 \\
8 \\
0 \\
8\end{array}$ \\
\hline
\end{tabular}

*Unmatched estimates 
Table 4 Risk factors for Creutzfeldt-Jakob disease identified in uncontrolled studies

\begin{tabular}{|c|c|}
\hline $\begin{array}{l}\text { Craniotomy }{ }^{5} \\
\text { Ferret contact }^{29} \\
\text { Sheep contact }{ }^{30} \\
\text { Eating sheep meat }{ }^{31}\end{array}$ & $\begin{array}{l}\text { Eating wild animal brains } \\
\text { Medical/paramedical profession } \\
\text { Family history of dementia } \\
\text { Fam }^{33}\end{array}$ \\
\hline
\end{tabular}

or surgical events according to the intervals before onset of disease employed by Davanipour et $a^{11}$ did not materially alter these findings. In the 2 years before onset only one case was known to have been examined by ocular tonometry compared with eight controls.

Diet and smoking. No association was found between smoking habits and risk of Creutzfeldt-Jakob disease. Cases were less likely than controls to be current alcohol drinkers $(p<0.005)$ (table 3). Cases and controls were reported to have similar histories of consumption of meat, liver and brain. Cases tended to eat less kidney than controls and more tripe. Cases were also more likely than controls to have ever eaten other forms of offal, though there was no clear evidence of a trend towards increased risk with higher consumption.

Animal contact. No significant association was observed between risk of Creutzfeldt-Jakob disease and having kept the following pets: dogs ( 50 cases; 81 controls), budgerigars $(15 ; 20)$, hamsters $(2 ; 4)$, rabbits $(3 ; 5)$. Cases were more likely than controls to have kept cats $(p<0.05)$, this difference being largely due to a deficit of cat owners among neurological controls (table 3), or pets other than those listed above $(\mathrm{p}<0.01)$, usually tropical fish or cage birds, and more likely to have allowed pets to mingle freely in the household. They were also more likely than controls to have lived in a household where ferrets $(p=0.05)$ or mink (Fisher's exact test, $p=0.08$ ) were kept. Cases were slightly more likely to have had contact with sheep $(13 ; 20)$, fur $(7 ; 8)$ and carcasses $(5 ; 7)$ but none of these associations was statistically significant.

Family history of dementia. The relatives were asked if there was a history of dementia in the siblings, children, parents or other relations of the cases and controls. In total such a history was given for 27 cases, eight medical and 11 neurological controls $(\mathrm{p}<$ 0.0005 ). Five cases and one control had two or more relatives with presenile dementia, the corresponding numbers for senile dementia being two cases and two controls. Four siblings of cases and three of controls were reported to have had dementia and one case and one control had children with dementia. Four cases and three controls had non-first degree relatives with dementia. No cases but four controls were reported to have had a father who died of dementia and the mothers of 13 cases and 10 controls were reported to have died of this cause. There was no instance of proven familial Creutzfeldt-Jakob disease in the casecontrol series and from the available descriptions it is probable that the majority of the demented relatives had Alzheimer's disease.

\section{Discussion}

We believe that our surveillance methods would have ascertained the great majority of cases of CreutzfeldtJakob disease that came to the attention of a neurologist during this period. The number of cases identified varied little from year to year and the average annual mortality rate of $0.49 /$ million was appropriately higher than the estimate of 0.31 /million from our earlier retrospective study in which underascertainment would certainly have been greater. ${ }^{18}$ Combining the present data with that study produces a total of 165 female and 106 male cases in the definite and probable diagnostic categories, a female to male ratio of $1.56: 1$. This difference is significant, even allowing for the different age distributions of the male and female populations $(p<0.025)$, a finding for which we have no explanation and which has not been observed in other population studies. ${ }^{19}$ Mortality rates, closely paralleling incidence in this subacute fatal disease, declined after the age of 74 years, a pattern similar to previous reports. ${ }^{18-20} \mathrm{~A}$ possible explanation of this decline is that ascertainment may be deficient in the very old. However, the rapid clinical course would probably seldom fail to arouse interest and there is nothing to suggest that the disease follows a different course at this age. If the true rates in those above 74 years were the same as those aged $70-74$ the under-ascertainment would have had to have been such that about three out of four cases in those over 74 were missed by our surveillance.

We were able to include in the case-control study only 92 of the 122 cases ascertained. We think it unlikely that the main reasons for exclusion, lack of an informed relative or long delay between death and ascertainment, will have introduced any substantial bias into the study. Potential controls were also excluded if a relative was unavailable.

Our study differed from previous case-control investigations in some important respects. Bobowick et $\mathbf{a l}^{\mathbf{8}}$ compared 38 "selected" cases of CreutzfeldtJakob disease with 35 relatives, usually the spouse, and 33 close friends. Kondo and Kuroiwa ${ }^{9}$ used the same method with larger numbers, comparing 60 cases with 47 spouses and 56 neighbours. Davanipour et $\mathrm{al}^{11-13}$ in a series of reports, compared 26 cases with 18 family and 22 hospital controls. Information on patients with Creutzfeldt-Jakob disease must 
necessarily be obtained from relatives but in all these studies the control subjects were questioned directly, sometimes by telephone. The effects on accuracy of information are impossible to determine, but there are obvious dangers in comparing data from such disparate sources. The extent, but not the quality, of information that can be obtained from relatives was examined by Pickle et al. ${ }^{21}$ Their conclusions emphasise the need to question relatives of the same degree to obtain comparable data and this practice was to a great extent adopted in the present study. There was, unfortunately, no way of obtaining reliable information on childhood events for these predominantly elderly subjects.

The search for environmental risk factors for Creutzfeldt-Jakob disease has concentrated on the possibility of the transmissible agent being introduced from a human or animal source, an alternative being activation of latent infection by trauma or disease. The theoretical possibilities are extensive as Creutzfeldt-Jakob disease can be transmitted in the laboratory from cerebral, ocular or peripheral tissues, including blood, by intracerebral or peripheral injection and by the oral route. ${ }^{22}$ The related scrapie agent can be transmitted in mice through the lightly traumatised gums. ${ }^{23}$ The agent can persist for long periods outside the body, for example in fixed stained pathological sections ${ }^{24}$ and is notoriously resistant to conventional means of sterilisation. Natural disease due to similar agents occurs in sheep, goats, mink and deer and can be transmitted to many other species.

A further obstacle to investigation is that if infection does indeed occur the incubation period is likely to be prolonged. By intracerebral or ocular infection the incubation period in man is about 17 months ${ }^{2-5}$ while the minimum incubation period when transmitted by peripheral injection of human growth hormone is $\mathbf{4}$ years and the mean period is probably very much longer. ${ }^{725-27}$ Kuru, transmissible by a similar agent, is thought to have been acquired orally or through skin abrasions and sometimes has an incubation period of 30 years. ${ }^{28}$

A number of possible risk factors for CreutzfeldtJakob disease have been suggested by uncontrolled observations (table 4). With the exception of ferret contact a significant difference between cases and controls was not found for any of these factors in the present study. No patient with Creutzfeldt-Jakob disease had previously had a craniotomy.

In the present series the affected medical practitioner and nurses had no contact with any known case of Creutzfeldt-Jakob disease. The close geographical propinquity of the dental surgeon to two cases of Creutzfeldt-Jakob disease has already been reported. ${ }^{5}$ We found that a history of dementia in close relatives was significantly much more common in cases of Creutzfeldt-Jakob disease than in controls, although in the great majority of demented relatives the history obtained did not resemble that of Creutzfeldt-Jakob disease. In the case-control study there was no instance of verified familial CreutzfeldtJakob disease. The associations we observed between risk of Creutzfeldt-Jakob disease and family history of dementia could have arisen from recall bias, relatives of cases being more likely to remember other demented family members than relatives of nondemented controls.

Risk factors identified as significant in controlled studies are outlined in table 5. None of these associations were confirmed in the present study. Surgery of any kind and trauma were less common at any age in cases than in controls. Although past events related to the present admission were ignored in our analysis, it is possible that the selection of hospital controls may have biased the control groups with regard to these potential risk factors. From our dietary enquiry we found weak associations with eating tripe and other offal and a negative association with eating kidneys. Similar associations have not been reported before and are probably chance findings. Meat consumption is known not to be universal in Creutzfeldt-Jakob disease as the disease has been described in a life-long vegetarian. ${ }^{34}$ The apparent protective effect of alcohol in the present series is probably explained by the role of alcohol as a risk factor for admission to hospital for other causes.

Davanipour $e t a l^{11}$ reported that a high proportion of both cases $(96 \%)$ and controls $(73 \%)$ had recently been examined by ocular tonometry. We found only one case and eight controls known to have been examined in this way within the same period. In the USA oculists, when testing patients for spectacles, routinely test ocular pressure by the direct contact method while this is not so in Britain although an indirect method is sometimes employed. Our limited data do not support the possible role of this procedure in transmitting Creutzfeldt-Jakob disease.

It is unlikely that our few positive findings are related in any way to the aetiology of CreutzfeldtJakob disease. When over a hundred factors are examined some statistically significant results are to be expected by chance. It could be postulated, for example, that previous mental disease marked the entry of the agent; that herpes zoster activated latent infection; or that infection was acquired from cats or ferrets, but there is little support for such intrinsically improbable theories.

There was no evidence of iatrogenic transmission in this series although this is known to occur. There was obviously a gross deficiency of reported surgical operations in childhood when tonsillectomy must have been very common. All the patients had received 
Table 5 Significant risk factors for Creutzfeldt-Jakob disease in controlled studies

\begin{tabular}{|c|c|c|}
\hline Author & Method & Risk factors \\
\hline Bobowick et $a l^{8}$ & $\begin{array}{l}38 \text { "selected" cases } \\
\text { healthy controls }\end{array}$ & None \\
\hline Kondo and Kuroiwa ${ }^{9}$ & $\begin{array}{l}\text { population study } \\
60 \text { cases } \\
\text { healthy controls }\end{array}$ & $\begin{array}{l}\text { Trauma in males } \\
\text { Surgery in } 5 \text { years } \\
\text { before onset }\end{array}$ \\
\hline Kondo ${ }^{10}$ & $\begin{array}{l}88 \text { autopsied cases } \\
\text { autopsied controls }\end{array}$ & Organ resection \\
\hline Davanipour et $a l^{11}$ & $\begin{array}{l}26 \text { cases } \\
40 \text { controls }\end{array}$ & $\begin{array}{l}\text { Trauma or surgery } \\
\text { to head or neck } \\
\text { Other trauma } \\
\text { Surgery needing } \\
\text { sutures } \\
\text { Tonometry }\end{array}$ \\
\hline Davanipour et $a l^{12}$ & as above & $\begin{array}{l}\text { Roast pork, ham } \\
\text { underdone meat, } \\
\text { "hot dogs" }\end{array}$ \\
\hline Davanipour et $a^{13}$ & as above & $\begin{array}{l}\text { Contact with fish, } \\
\text { rabbits, squirrels }\end{array}$ \\
\hline
\end{tabular}

dental treatment and this is a plausible means of transmission although unsupported by any evidence. Regrettably, two easily ascertained possible methods of introducing the agent, ear piercing and tattooing, were not routinely recorded. The former would, in this generation, favour female preponderance, while tattooing is far more common in men.

Familial clustering of Creutzfeldt-Jakob disease is well recognised, occurring in from 6 to $26 \%$ in population studies. ${ }^{181935}$ In the present series we found only one of 111 cases with a verified family history and four where Creutzfeldt-Jakob disease in a relative was thought possible. It is difficult to distinguish vertical transmission of the disease from the effects of increased exposure or susceptibility to infection. Cathala $e t a l^{36}$ have suggested that all CreutzfeldtJakob disease, except iatrogenic cases, may be genetic and that sporadic cases only appear to be so because their susceptible relatives have not lived long enough to develop the disease. If this is so the search for environmental factors will be fruitless. An alternative often considered, however, is that the incidence of infection is substantially greater than that of disease, but we were unable to detect environmental factors that might lead to transmission of the agent or influence whether or not a susceptible individual will manifest Creutzfeldt-Jakob disease.

We thank all those who referred cases of known or suspected Creutzfeldt-Jakob disease to our study, and all who patiently answered our questions. We are greatly indebted to Dr Trevor Hughes and Dr Ivan Janota for ensuring a high necropsy rate in this study. The investigation was supported by the Medical Research Council.

\section{References}

1 Gibbs CJ Jr, Gajdusek DC, Asher DM, Beck E, Daniel PM, Matthews WB. Creutzfeldt-Jakob disease (spongiform encephalopathy); transmission to the chimpanzee. Science 1968;161:388-9.

2 Duffy F, Wolf J, Collins G, Devoe A, Streeten B, Cowen D. Possible person-to-person transmission of Creutzfeldt-Jakob disease. N Eng J Med 1974;290:692-3.

3 Bernoulli C, Siegfried J, Baumgartner G, et al. Danger of personto-person transmission of Creutzfeldt-Jakob disease by surgery. Lancet 1977;1:478-9.

4 Foncin JF, Gaches J, Cathala F, el Sherif E, le Beau J. Transmission iatrogène interhumaine possible de maladie de Creutzfeldt-Jakob avec atteinte des grains du cervelet. Rev Neurol (Paris) 1980;136:280.

5 Will RG, Matthews WB. Evidence for case-to-case transmission of Creutzfeldt-Jakob disease. J Neurol Neurosurg Psychiatry 1982;45:235-8.

6 Brown P, Gajdusek DC, Gibbs CJ Jr, Asher DM. Potential epidemic of Creutzfeldt-Jakob disease from human growth hormone. $N$ Engl J Med 1985;313:728-31.

7 Powell-Jackson J, Weller RO, Kennedy P, Whitcombe EM, Newsom-Davis J. Creutzfeldt-Jakob disease after administration of human growth hormone. Lancet 1985;ii:244-6.

8 Bobowick AR, Brody JA, Matthews MR, Roos R, Gajdusek DC. Creutzfeldt-Jakob disease: a case-control study. Am J Epidem 1973;98:381-94.

9 Kondo K, Kuroiwa Y. A case control study of Creutzfeldt-Jakob disease: association with physical injuries. Ann Neurol 1982;11:377-81.

10 Kondo K. 1985 Epidemiology of Creutzfeldt-Jakob disease in Japan. In: Mizutani T, Shiraki H, eds. Clinicopathological Aspects of Creutzfeldt-Jakob Disease in Japan. Nishimura: Elsevier 1985:17-30.

11 Davanipour Z, Alter M, Sobel E, Asher DM, Gajdusek DC. Creutzfeldt-Jakob disease: possible medical risk factors. Neurology 1985;35:1483-6.

12 Davanipour Z, Alter M, Sobel E, Asher DM, Gajdusek DC. A case-control study of Creutzfeldt-Jakob disease: dietary risk factors. Am J Epidemiol 1985;122:443-51.

13 Davanipour Z, Alter M, Sobel E, Asher DM, Gajdusek DC. Transmissible virus dementia: evaluation of a zoonotic hypothesis. Neuroepidemiology 1986;5:196-206.

14 Gail MH, Lubin JH, Rubenstein LV. Likelihood calculations for matched case-control studies and survival studies with tied death time. Biometrike 1981;68:703-7.

15 Will RG, Matthews WB. A retrospective study of CreutzfeldtJakob disease in England and Wales 1970-1979. I. Clinical features. J Neurol Neurosurg Psychiatry 1984;47:134-40.

16 Salazar AM, Masters CL, Gajdusek DC, Gibbs CJ Jr. Syndromes of amyotrophic lateral sclerosis and dementia: relation to transmissible Creutzfeldt-Jakob disease. Ann Neurol 1983;14:17-26.

17 Brown P, Rodgers-Johnson P, Cathala F, Gibbs CJ Jr, Gajdusek DC. 1984 Creutzfeldt-Jakob disease of long duration; clinicopathological characteristics, transmissibility, and differential diagnosis. Ann Neurol 1986;16:295-304.

18 Will RG, Matthews WB, Smith PG, Hudson C. A retrospective study of Creutzfeldt-Jakob disease in England and Wales 1970-1979. II: Epidemiology. J Neurol Neurosurg Psychiatry 1986;49:749-55

19 Brown P, Cathala F, Raubertas R, Gajdusek DC, Castaigne P. The epidemiology of Creutzfeldt-Jakob disease: conclusion of a 15-year investigation in France and review of the world literature. Neurology 1987;37:895-904.

20 Brown P, Cathala F, Gajdusek DC. Creutzfeldt-Jakob disease in France: III. Epidemiological study of 170 patients dying during the decade 1968-77. Ann Neurol 1979;6:438-46.

21 Pickle LW, Brown LM, Blot WJ. Information available from sur- 
rogate respondents in case-control studies. Am J Epidemiol 1983;118:99-108.

22 Gibbs CJ Jr, Amyx HL, Bacote A, Masters CL, Gajdusek DC Oral transmission of kuru, Creutzfeldt-Jakob disease and scrapie to non-human primates. J Infect Dis 1980;142:205-8.

23 Adams DH, Edgar WM. Transmission of agent of CreutzfeldtJakob disease. $\mathrm{Br}$ Med $J$ 1978;1:987.

24 Brown P, Gibbs CJ Jr, Gajdusek DC, Cathala F, LaBauge R Transmission of Creutzfeldt-Jakob disease from formalin fixed, paraffin-embedded human brain tissue. $N$ Engl $J$ Med 1986:515:1614-5.

25 Gibbs CJ Jr, Joy A, Heffner R, Franko M, Miyazaki M, Asher DM, Parisi JE, Brown PW, Gajdusek DC. Clinical and pathological features and laboratory confirmation of Creutzfeldt-Jakob disease in a recipient of pituitary-derived human growth hormone. $N$ Engl J Med 1985;313:734-8.

26 Koch TK, Berg BO, de Armond SJ, Gravina RF. CreutzfeldtJakob disease in a young adult with idiopathic hypopituitarism. N Engl J Med 1985;313:730-3.

27 Tintner R, Brown P, Hedley-White ET, Rappaport EB, Piccardo CP, Gajdusek DC. Neuropathologic verification of Creutzfeldt-Jakob disease in the exhumed American recipient of human pituitary growth hormone. Neurology 1985;36:932-6.

28 Klitzman RL, Alpers MP, Gajdusek DC. The natural incubation of kuru and the episodes of transmission in three clusters of patients. Neuroepidemiology 1984;3:3-20.

29 Matthews WB, Campbell M, Hughes JT, Tomlinson AH. Creutzfeldt-Jakob disease and ferrets. Lancet 1979;i:828.

30 Lo Russo F, Neri G, Figá-Talamanca L. Creutzfeldt-Jakob disease and sheep brain: a report from central and southern Italy. Ital J Neurol Sci 1980;3:171-4.

31 Alter M, Frank Y, Doyne H, Webster D. Creutzfeldt-Jakob disease after eating ovine brains? N Engl J Med 1975;292:927.

32 Kamin M, Patten BM. Creutzfeldt-Jakob disease. Possible transmission by consumption of wild animal brains. Am J Med 1984;76:142-5.

33 Masters CL, Harris JO, Gajdusek DC, Gibbs CJ Jr, Bernoulli C Asher DM. Creutzfeldt-Jakob disease: patterns of worldwide occurrence and the significance of familial and sporadic clustering. Ann Neurol 1978;5:177-88.

34 Matthews WB, Will RG. Creutzfeldt-Jakob disease in a lifelong vegetarian. Lancet 1981;ii:937.

35 Gálvez S, Masters CL, Gajdusek DC. Descriptive epidemiology of Creutzfeldt-Jakob disease in Chile. Arch Neurol 1980;37:11-14.

36 Cathala F, Brown P, Chatelain J, Castaigne P, Gajdusek DC. Maladie de Creutzfeldt-Jakob en France. Interêt des formes familiales. Existe-t-il un gène gouvernant la durée de l'incubation. Presse Méd 1986;15:379-82. 